\title{
ERJ
}

Engineering Research Journal

Faculty of Englneering

Mnnouflya Unlversity

\section{IMPACT RESISTANCE OF RUBBERIZED CONCRETE}

\author{
H. E. M. Sallam, A. S. Sherbini, M. H. Seleem and M. M. Balaha \\ Materials Engineering Department, Zagazig University, Zagazig, Egypt
}

\begin{abstract}
In the present paper, an experimental work was carried out to study the effect of ground waste tire rubber addition on the mechanical properties and impact resistance of normal strength concrete (NSC) with and without silica fume. Three different volume ratios of crumb rubber $(10 \%, 20 \%$, and $30 \%$ ) were used as a partial replacement of sand. Two different sizes of cylinders were tested under indirect tension test to study the size effect. Impact compression according to ACl Committee 544's repeated drop-weight impact test was carried out on discs of $150 \mathrm{~mm}$ diameter and $63 \mathrm{~mm}$ height. Test results showed that, the replacement of fine aggregate by $10 \% \mathrm{crumb}$ rubber caused a small decrease in concrete compressive strength. The presence of crumb rubber of small size in concrete increased its resistance to crack initiation under impact load. The rubber of small size has no particle bridging effect, hence, the mode of failure of rubberized concrete under static and impact compression was the same as that of plain concrete. The ACI impact test failed to differentiate between the impact resistance of rubberized concretes with different rubber contents.

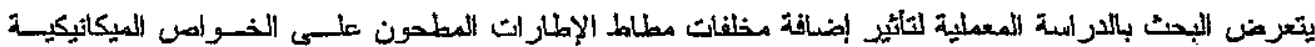

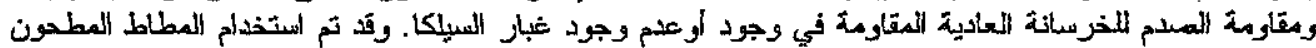

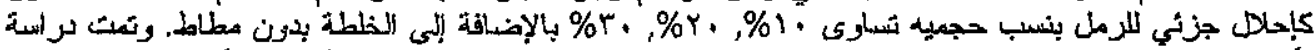

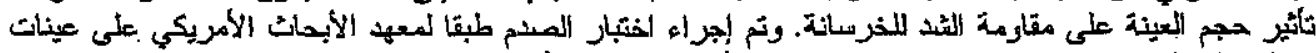

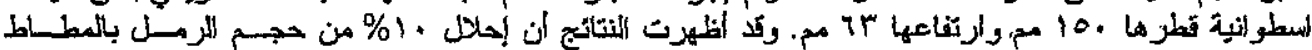

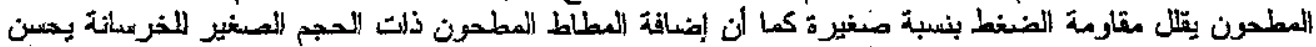

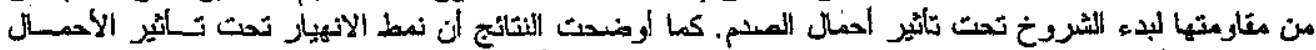

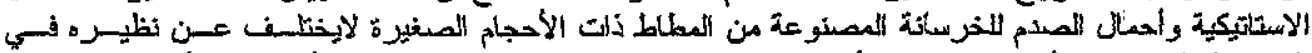

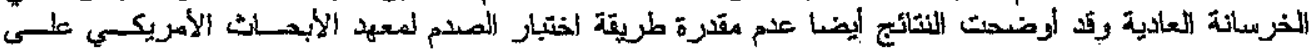

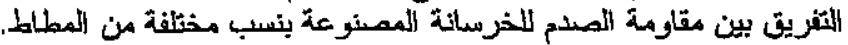

Keywords: Rubberized concrete; Impact resistance; Drop weight impact test; Silica fume

\section{INTRODUCTION}

Waste tires pose a health hazard since tire piles are excellent breeding grounds for mosquitoes. Because of the shape and impermeability of tires, they may hold water for long periods providing sites for mosquito larvae development. Waste tires also pose a serious fire hazard since waste tires and waste tire stockpiles are difficult to ignite. However, once ignited tires burn very hot and are very difficult to extinguish. This is due to the $75 \%$ void space present in a whole waste tire, which makes it difficult to quench the tires with water or to eliminate the oxygen supply. In addition, the doughnut-shaped tire casings allow air drafts to stoke the fire. A large tire fire can smolder for several weeks or even months, sometimes with dramatic effect on the surrounding environment. An end-of-life tire is a used tire that cannot or is not reused for its originally intended purpose and is not retreated. Such tires may have a further use as a raw material for other processes or be destined for final disposal. End-of-life tires are called "scrap tires" in the United States [1].
The possibility of making concrete tough has been generally pursued by introducing rubber phases among the traditional components (cement, water and aggregates) and this idea has been largely investigated using, for this purpose, recycled grinded tire rubbers [2-7]. Different kinds of tires have been employed as partial substitute of natural aggregates in concrete: scrap tires obtained by simple grinding without further purifications thus including steel and textile fibers in their composition $[2,4]$, crumb rubber obtained by cryogenic process [2], milled tire rubbers treated with sodium hydroxide solution to achieve a better adhesion with the cement paste [7], scrap truck tire rubber [5], tires tread [3], etc. However, regardless the different nature, size and composition of used tire rubbers, a meaningful decrease in concrete compressive strength with the increasing amount of rubber phase in the mixture was always detected. Although the so far obtained rubberized concrete generally shows tougher behavior with a gradual failure of the samples than traditional concrete," it generally does not exhibit suitable 
compressive strength for structural applications [8]. The purpose of aggregating rubber is to increase concrete's flexibility, elasticity, and capacity to absorb energy. According to the results of the experiments, it was determined that the addition of rubber aggregate into concrete does in fact increase concrete's impact resistance. This resistance is derived from rubberized concrete's increased ability to absorb energy, safety; and insulate sound during impact. Furthermore, the increase in these properties became mole prominent in the concrete samples aggregated with larger rubber aggregate. These altered characteristics are attributed to aggregated rubber because of its filer structure, which gives the concrete its flexibility and capacity to take in strokes. This increase in elasticity and ability to absorb energy greatly reduces the damage incurred by vehicles colliding with parapets in highway barriers. With this in mind, vehicle impacts taking piace with these concrate barriers have been approached as collision problems [9].

Despite the significant increase in the impact resistance of concrete due to the addition of fiber or rubber, researchers and designers are not able to use impact resistance as a design parameter, simply because it cannot be fully quantified due to the lack of a standard impact test for concrete. The absence of a standard impact test prompted researchers to propose their own impact tests to estimate the impact resistance of concrete, either quantitatively or qualitatively. Some of these tests are relatively difficult to perform and require sophisticated equipment. None of these tests, however, have been claimed to be a standard test due to the lack of statistical data on the variation of the results [10]. In this regard, ACI Committee 544 [11] has proposed a drop weight impact test to demonstrate the relative brittleness and to quantify the impact resistance of fiber-reinforced concrete (FRC). The test is widely used because it is simple and economical. The results obtained from this test are often noticeably scattered. The large variation in impact resistance as determined from this test is reported in the literature for different types of FRC. Large variation is a common problem in impact testing, and it is difficult to devise systems that give reproducible results. This might be attributed to the nature of the impact process itself and the number of factors controlling the impact resistance compared with other mechanical properties $[10,12]$. The main objective of the present work is to study the effect of ground waste tire rubber as a partial replacement of sand on the mechanical properties and impact resistance of normal strength concrete (NSC) with and without silica fume. Three different volume ratios of crumb rubber $(10 \%, 20 \%$, and $30 \%)$ were used as a partial replacement of the sand.

\section{EXPERIMENTAL WORK}

All test specimens were fabricated using locally available materials. Type I ordinary Portiand cement was utilized. Silica fiume from the Ferro silicon alloys plant in Edfo zone, Egypt, was used. All the bags of silica fume had not any indication for the date of production and the expired date. Therefore, the used silica fume was stored in good storing conditions for two years to examine its validity. The sand used was local natural siliceous sand with specific gravity of 2.55. The coarse aggregate used was dolomite with maximum aggregate size of $14 \mathrm{~mm}$ and specific gravity of 2.6. A superplasticizer called Adecrite PVF (naphthalene sulphonated cornpound) was chosen. The used crumb rubber in this research was produced by (El-Nasr Tire Company) by grinding the waste tires with special technique. Table 1 shows the passing percentage of crumb rubber.

In this study, three different volume ratios of crumb rubber $(10 \%, 20 \%$, and $30 \%)$ were used as a replacement of the sand and two different cementatious material contents of $443 \mathrm{Kg} / \mathrm{m}^{3}$ cement and $\left(443 \mathrm{Kg} / \mathrm{m}^{3}\right.$ cement $+10 \%$ silica fume from cement weight) were used. The concrete mix proportions by weight for the iwo mixes was (1 cement: 1.34 sand: 2.246 dolomite: 0.34 water: 0.01 , by weight of cement- SF, super-plasticizer). Cubes $150 \times 150 \times 150 \mathrm{~mm}$ were prepared to be tested under static compression. Two different sizes of cylinders of $100 \mathrm{~mm}$ diameter and $200 \mathrm{~mm}$ height and $150 \mathrm{~mm}$ diameter and $300 \mathrm{~mm}$ height were prepared to be tested under indirect tension test to study the size effect. On the other hand, discs of 150 $\mathrm{mm}$ diameter and $63 \mathrm{~mm}$ height were cast to be tested under impact cornpression according to $\mathrm{ACI}$ Committee 544 's repeated drop-weight impact test. Concrete specimens were cast in steel moulds. After 24 hours the specimens were de-molded and water cured for 28 days. All specimens were cast and treated under the same environmental conditions.

Table 1 Passing percentage of crumb rubber.

\begin{tabular}{|c|c|}
\hline Sieve Opening, mm & Passing \% \\
\hline 5 & 90 \\
\hline 2.5 & 54 \\
\hline 1.25 & 26 \\
\hline 0.2 & 5 \\
\hline 0.31 & 1 \\
\hline 0.16 & 0 \\
\hline
\end{tabular}

Special impact machine was designed and fabricated at the laboratories of Zagazig University adopting the technique of drop weight impact test. The impact machine was manufactured according to ACI recommendations; Fig. 1 shows the test rig. A brief of the test is that, the samples are coated on the 


\section{H. Sallam, A. Sherbini, M. Seleem, M. Balaha, "Impact Resistance Of Rubberized Concrete"}

bottom with a thin layer of petroleum jelly or a heavy grease and placed on the base plate within the positioning lugs with the finished face up (if appropriate). The positioning bracket is then bolted in place, and the hardened steel ball is placed on top of the specimen within the bracket. The drop hammer is placed with its base upon the steel ball and held there with just enough down pressure to keep it from bouncing off the ball during the test. The base plate should be bolted to a rigid base, such as a concrete floor or cast concrete block. The hammer is dropped repeatedly, and the number of blows required to cause the first visible crack on the top and to cause ultimate failure are both recorded. Ultimate failure is defined as the opening of cracks in the specimen sufficiently so that the pieces of concrete are touching three of the four positioning lugs on the base plate. Results of these tests exhibit a high variability and may vary considerably with the different types of mixtures, fiber contents, etc.
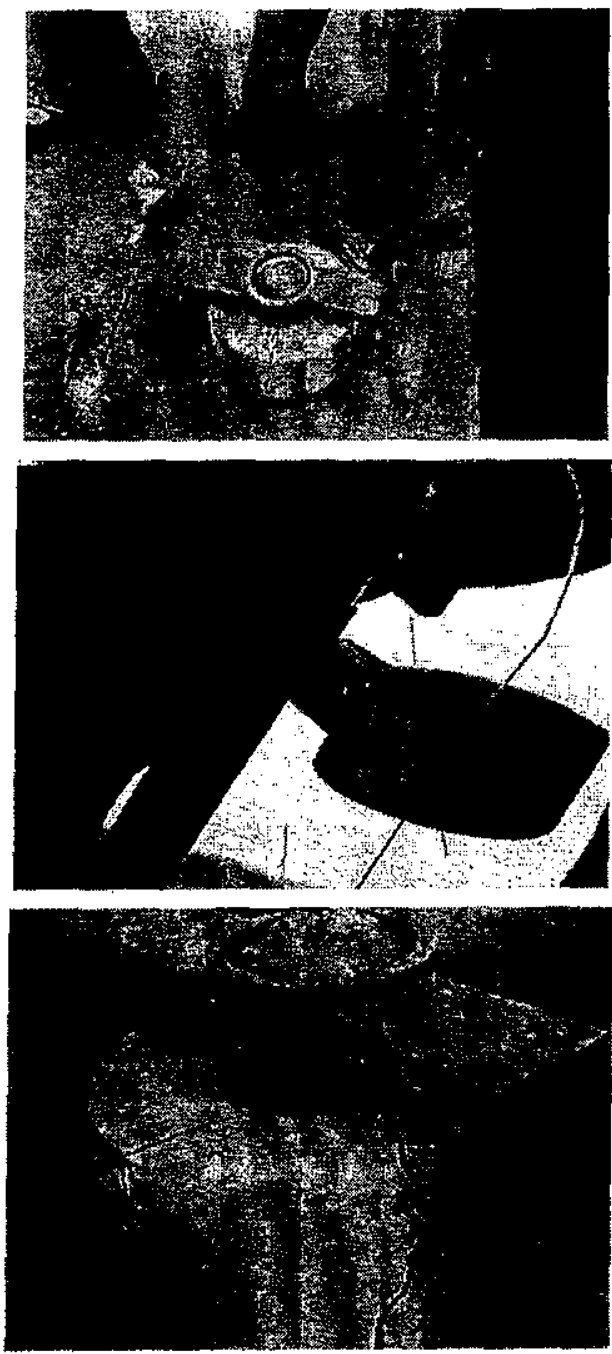

Fig. 1 Impact test

\section{RESULTS AND DISCUSSIONS}

The mean values of measured compressive strength and splitting tensile strength for different plain and rubberized concretes are presented in Table 2 . Generally, the presence of silica fume causes small improvement in the compressive strength. This may be due to the long time of storage. The long storage time of silica fume made it absorb humidity from the surrounding atmosphere and so form large particles (i.e. decreasing fineness). This may affect its physical and chemical effect. There is also a reduction in concrete compressive and tensile strength due to the replacement of sand by crumb rubber with different volume fractions. It is clear that, there is a small reduction in the case of $10 \%$ replacement. Therefore, it can be concluded that, the $10 \%$ replacement of fine aggregate by crumb rubber has a marginal effect on concrete compressive strength. Although there is a small effect of silica fume addition in PC concrete, the rubberized concrete with silica fume showed bigher compressive strength than those without silica furie This is because the presence of silica fume in thenese of rubberized concrete enhanced the bond strengutu between the rubber particles and the cement paste [13]. There is no clear trend for the size effect on the indirect tensile strength measured from $10 \times$ $20 \mathrm{~cm}$ and $15 \times 30 \mathrm{~cm}$ cylinders. The mode of failures for various, rubberized concretes under compression indirect tension loads are the same as those of plain concrete. This may be due to small amount of rubber content and the small size of rubber particle in the mixes.

The simplest of the impact tests is the "repeated impact," drop-weight test. This test yields the number of blows necessary to cause prescribed levels of distress in the test specimen. This number serves as a qualitative estimate of the energy, absorbed by the specimen at the levels of distress specified. The test can be used to compare the relative merits of different rubber-concrete mixtures and to demonstrate the improved performance of rubberized concrete compared to conventional concrete. Figure 2 shows the crack pattern and the associated level of visible damage due to the impact force for either plain concrete or rubberized concrete. It is clear that, all specimens are divided to separate parts under the effect of impact force. No visible cracks were observed in each of the separated parts and no dislocated dolomite particles were found across the fractured surface. This may be due to the good bond between the mortar and the dolomite. Therefore, the favorable crack path is across the dolomite particles not around the surface of the particles. There is no particle bridging found in the case of rubberized concrete due to the small size of the crumb rubber. Particle bridging may be occurred in the case of large crumb rubber. 
Table 2 Mechanical properties of plain and rubberized concretes

\begin{tabular}{|c|c|c|c|c|c|c|c|c|}
\hline Crumb Rubber\% & \multicolumn{2}{|c|}{$0.0 \%$} & \multicolumn{2}{|c|}{$10 \%$} & \multicolumn{2}{|c|}{$20 \%$} & \multicolumn{2}{|c|}{$30 \%$} \\
\hline Silica Fume\% & $0.0 \%$ & $10 \%$ & $0.0 \%$ & $10 \%$ & $0.0 \%$ & $10 \%$ & $0.0 \%$ & $10 \%$ \\
\hline$f_{c k}, \mathrm{MPa}$ & 37.93 & 38.44 & 35.56 & 38.3 & 31.85 & 34.00 & 30.00 & 32.30 \\
\hline$f_{s p+15 * 30, \mathrm{MPa}}$ & 4.53 & 4.69 & 3.89 & 3.04 & 3.25 & 3.29 & 2.67 & 2.97 \\
\hline$f_{\mathrm{sp} 10^{*} 20,} \mathrm{MPa}$ & 3.98 & 3.61 & 4.08 & - & 2.97 & 4.35 & 4.14 & - \\
\hline
\end{tabular}

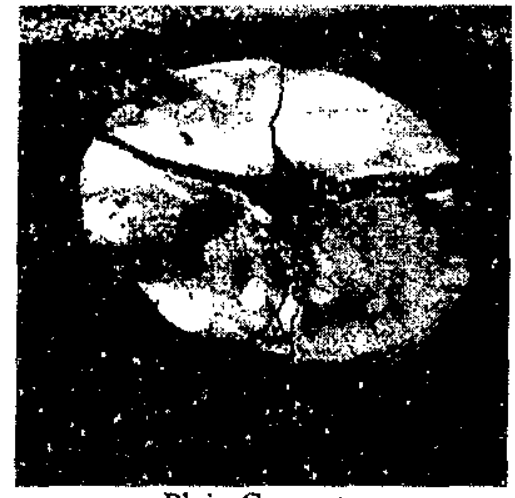

Plain Concrete

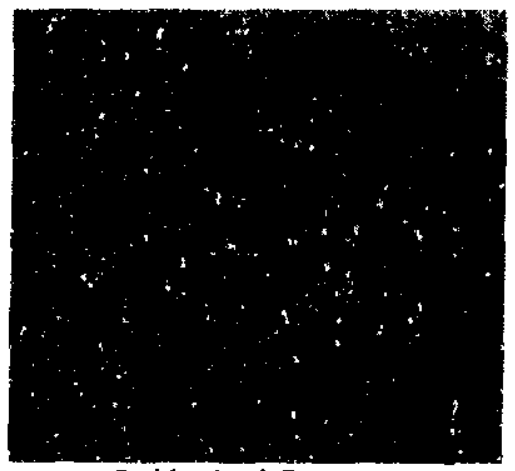

Rubberized Concrete

Fig. 2 Mode of failure plain and rubberized concretes under impact load.

Figures 3 and 4 show the number of blows till first crack occurs for nine specimens for the rubberized concrete without and with $10 \%$ silica fume addition respectively. It is clear that, there is a wide discrepancy in the results for all rubber replacernent ratios. A wide range in results of about $3-4$ times the mean value of the number of blows is observed. This wide range comes from the philosophy of the test itself not from any wrong steps in test procedures. The statistical analysis of the results of first crack is made in Table 3. The addition of silica fume has not clear effect on the resistance of concrete to crack initiation under impact compression load. The replacement of sand by crumb rubber increased the resistance of concrete to crack initiation under impact compression load. The ACI impact test failed to differentiate between the rubberized concretes with different rubber contents.

Figures 5 and 6 show the number of blows till failure occurs for nine specimens for the rubberized concrete without and with $10 \%$ silica fume addition respectively. The same behavior was found as in the case of first crack. Table 5 indicates that, the ratio of complete failure to the first crack is slightly above the unity (ranged from 1.03 to 1.14), i.e. the failure takes place rapidly in rubberized concrete. Therefore, we can claim that, the rubber with small size (no particle bridging) has a little effect to delay the crack propagation in concrete. Generally, adding the rubber to the concrete results in a significant increase in the number of blows.

Figures 7 and 8 sinow the statistical analysis of the results of complete failure for the rubberized concrete without and with $10 \%$ silica fume addition respectively. The range and the standard deviation are extremely high.

Table 3 Statistical analysis of number of blows to first crack

\begin{tabular}{|c|c|c|c|c|c|}
\cline { 2 - 6 } & Rubber \% & Silica Fume \% & Mean (blows) & Range/mean & C.0.V.* \\
\hline C & 0 & 0 & 35 & 4.83 & 1.74 \\
\hline SC & & 10 & 39 & 3.69 & 1.20 \\
\hline R1 & 10 & 0 & 290 & 3.80 & 1.21 \\
\hline SR1 & & 10 & 62 & 4.67 & 1.80 \\
\hline R2 & 20 & 0 & 67 & 10.75 & 3.58 \\
\hline SR2 & 20 & 10 & 177 & 3.47 & 1.40 \\
\hline R3 & 30 & 0 & 140 & 6.90 & 2.32 \\
\hline SR3 & & 10 & 63 & 3.95 & 1.32 \\
\hline
\end{tabular}

* C.O.V is the coefficient of variance 
H. Sallam, A. Sherbini, M. Seleem, M. Balaha, "Impact Resistance Of Rubberized Concrete"

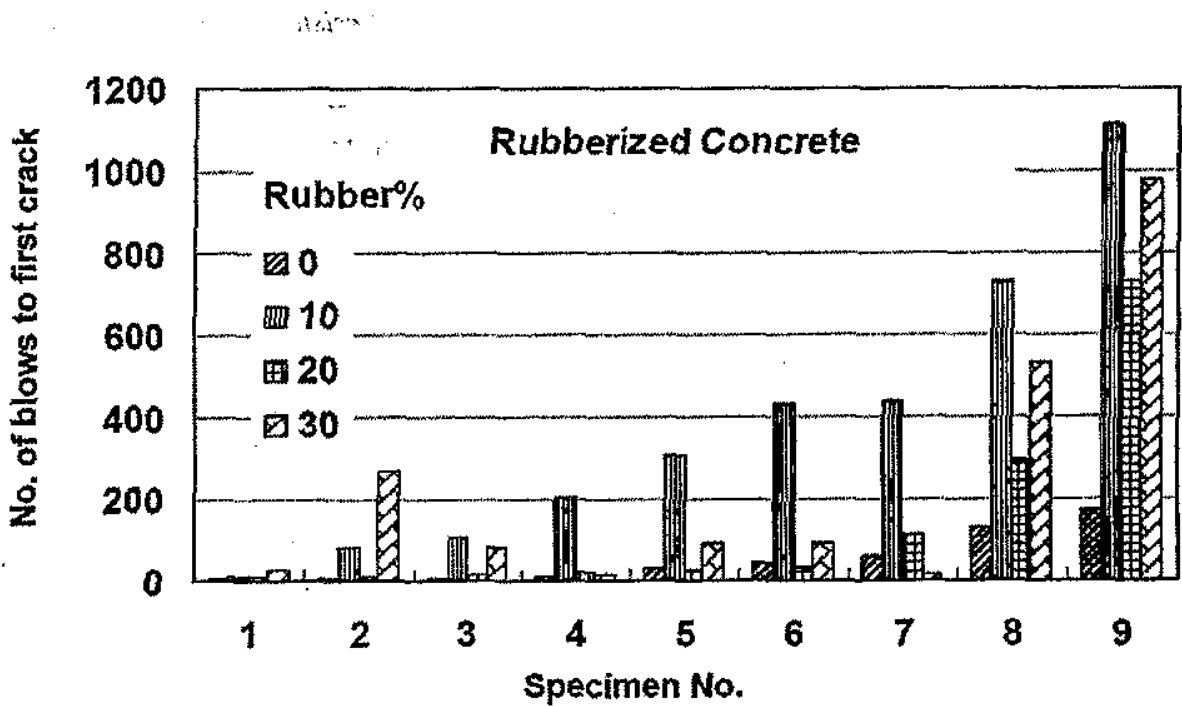

Fig. 3 Number of blows to first crack in rubberized concrete without silica fume

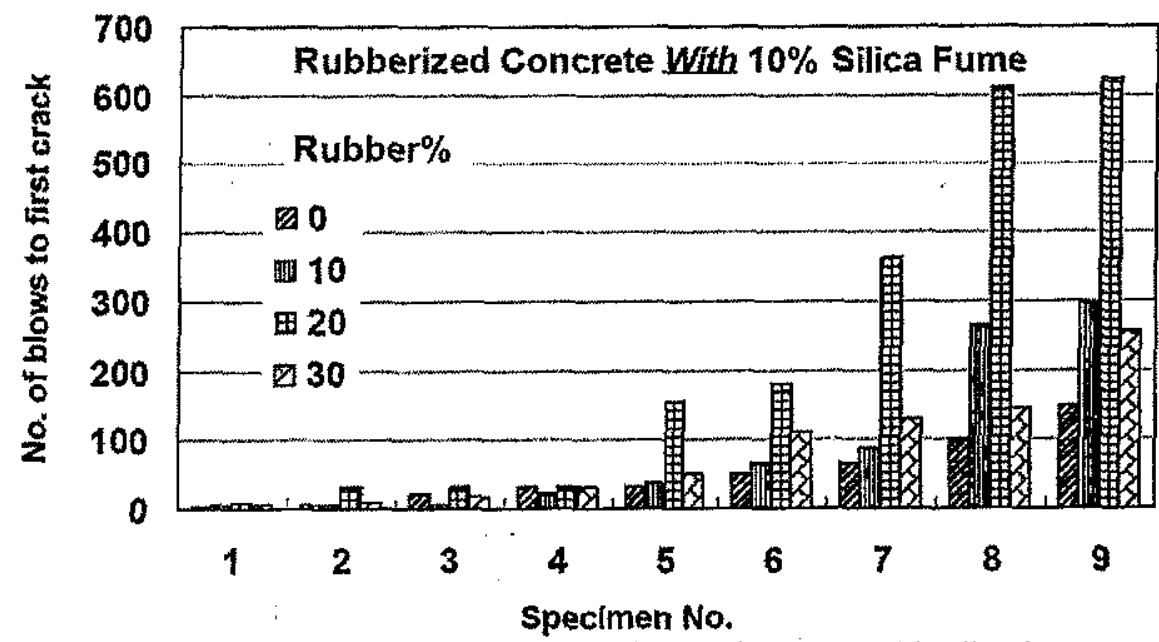

Fig. 4 Number of blows to first crack in rubberized concrete with silica fume.

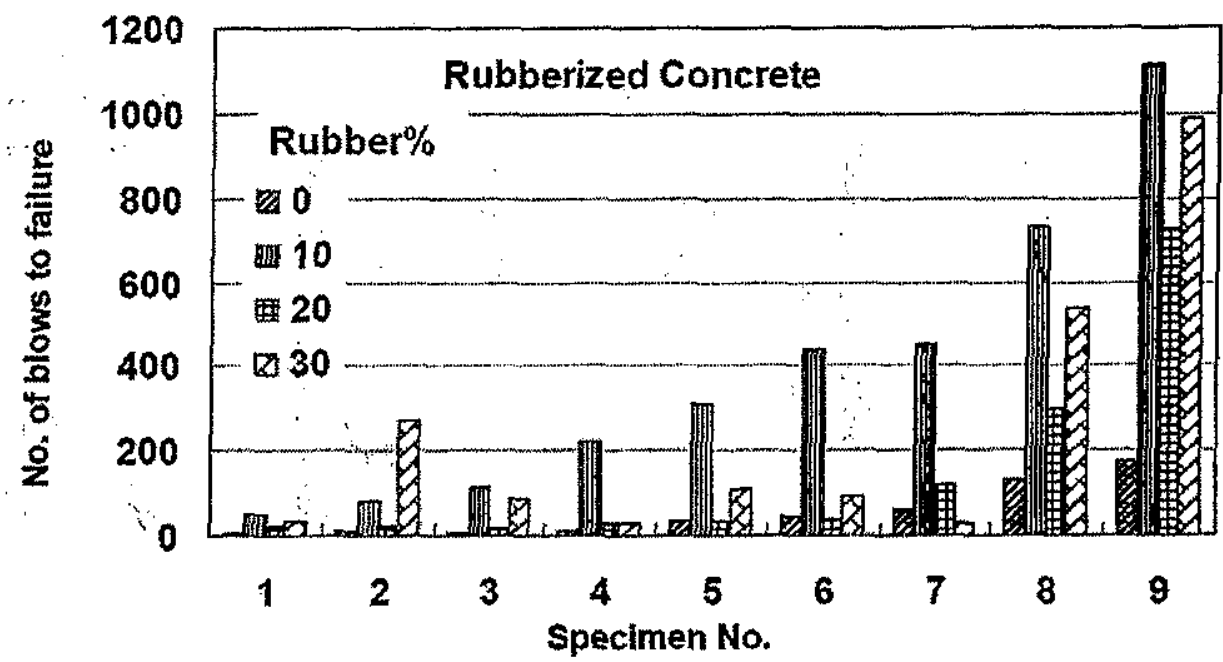

Fig. 5 Number of blows to failure cracks in rubberized concrete without silica 


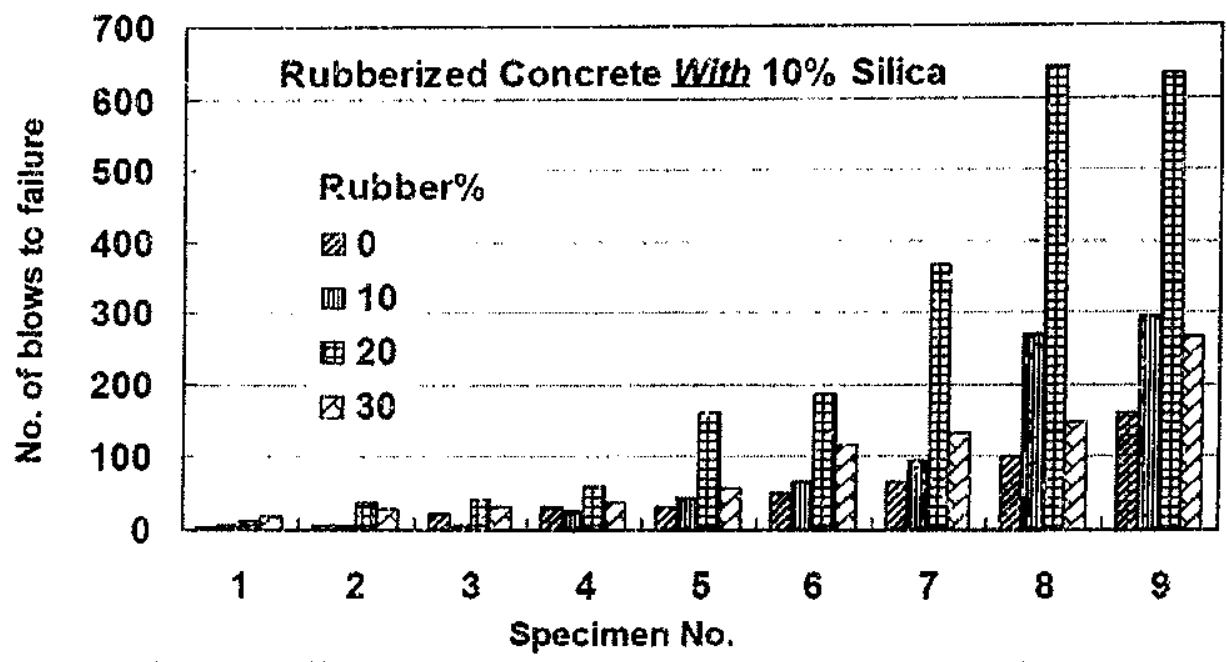

Fig. 6 Number of blows to failure cracks in rubberized concrete with silica fume

Table 5 Statistical analysis of rubberized concrete

\begin{tabular}{|c|c|c|c|c|c|c|c|}
\hline & \multicolumn{2}{|c|}{ without silica fume } & & & \multicolumn{2}{|c|}{ with silica fume } \\
\hline & & Mean (biows) & Failure / $1^{\text {st }}$ Crack & & & Mean (biows) & Failure / $1^{\text {II }}$ Crack \\
\hline \multirow{2}{*}{ C } & $l^{s t}$ crack & 35 & \multirow{2}{*}{1.06} & \multirow{2}{*}{ SC } & $I^{\text {st }}$ crack & 39 & \multirow{2}{*}{1} \\
\hline & Failure & 37 & & & Failure & 39 & \\
\hline \multirow{2}{*}{$R I$} & $I^{s t}$ crack & 290 & \multirow{2}{*}{1.03} & \multirow{2}{*}{$S R 1$} & $I^{s t}$ crack & 62 & \multirow{2}{*}{1.05} \\
\hline & Failure & 300 & & & Failure & 65 & \\
\hline \multirow[t]{2}{*}{$R 2$} & $1^{\text {st }}$ crack & 67 & \multirow{2}{*}{1.07} & \multirow{2}{*}{$S R 2$} & $1^{s t}$ crack & 177 & \multirow{2}{*}{1.07} \\
\hline & Failure & 72 & & & Failure & 189 & \\
\hline \multirow{2}{*}{$R 3$} & $I^{\text {st }}$ crack & 140 & \multirow{2}{*}{1.05} & \multirow{2}{*}{$S R 3$} & $I^{\text {st }}$ crack & 63 & \multirow{2}{*}{1.14} \\
\hline & Failure & 147 & & & Failure & 72 & \\
\hline
\end{tabular}

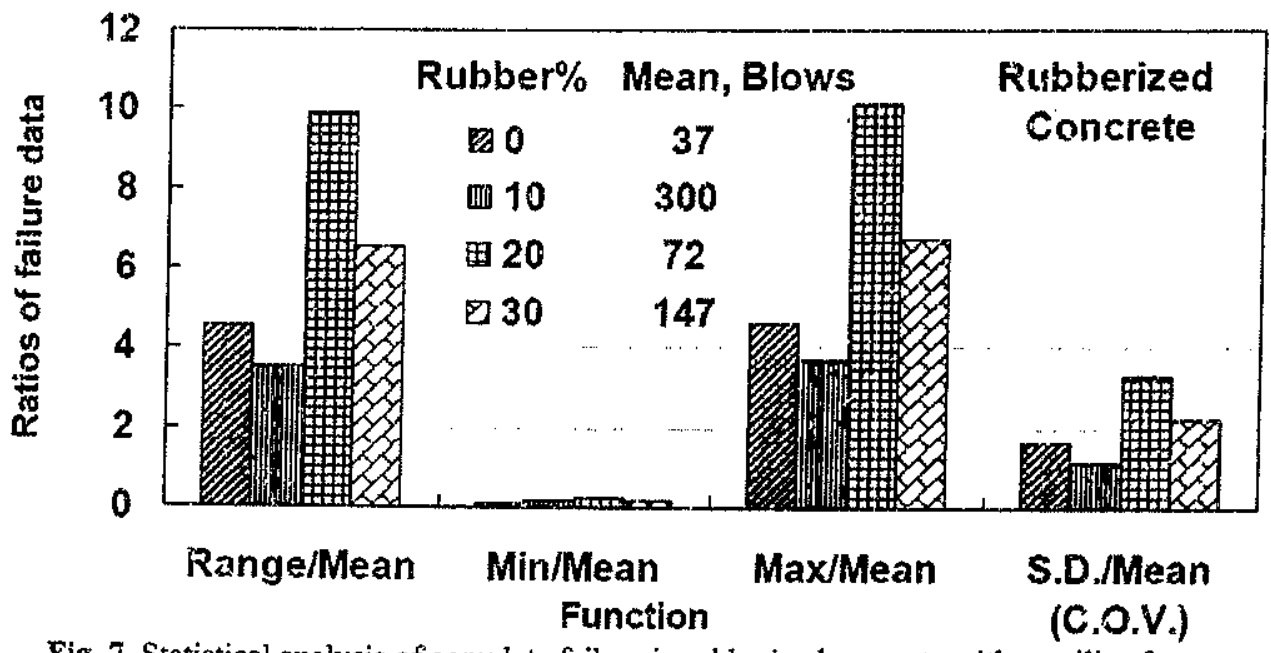

Fig. 7 Statistical analysis of complete failure in rubberized concrete without silica fume 
H. Sallam, A. Sherbini, M. Seleem, M. Balaha, "Impact Resistance Of Rubberized Concrete"

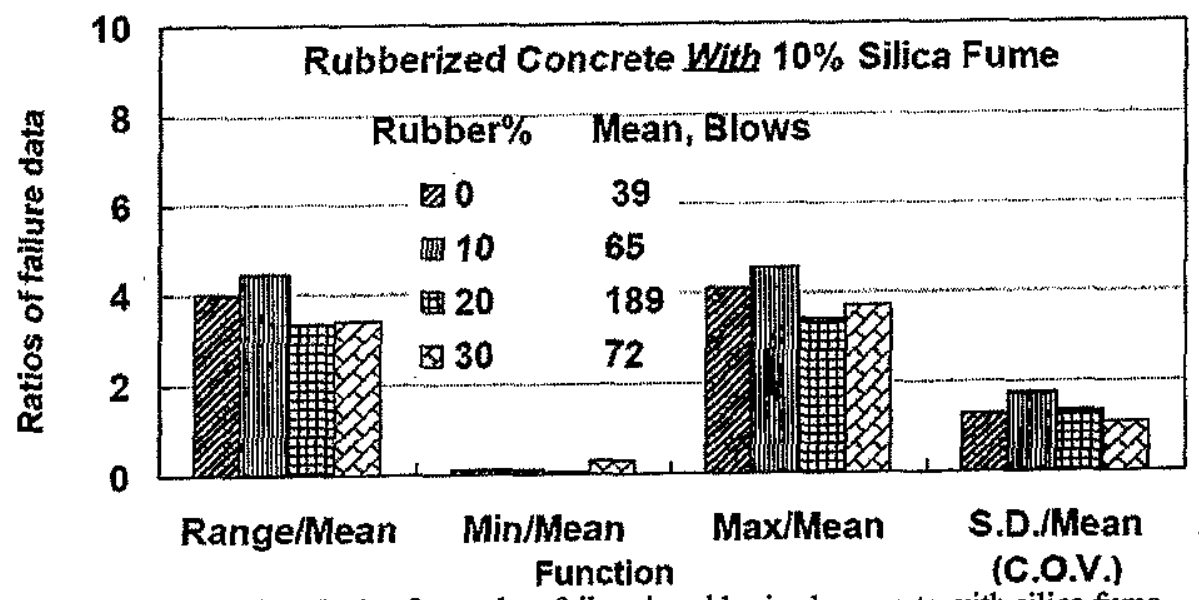

Fig. 8 Statistical analysis of complete failure in rubberized concrete with silica fume

\section{CONCLUSIONS}

From the experimental results obtained in this study, the following conclusions can be drawn:

1. There was a reduction in concrete compressive and tensile strength due to the replacement of sand by crumb rubber with different volume fractions.

2. The $10 \%$ replacement of fine aggregate by crumb rubber caused a small decrease in concrete compressive strength.

3. The presence of crumb rubber of small size in concrete increased the resistance of concrete to crack initiation under impact load.

4. The rubber of small size had no particle bridging effect, bence, the mode of failure of rubberized concrete under static and impact compression was the same as that of plain concrete.

5. The effect of silica fume addition on the compressive was more obvious in the case of rubberized concrete compared to plain concrete.

6. The ACI impact test failed to differentiate between the impact resistance of rubberized concretes with different rubber contents.

\section{REFERENCES}

[1] URL:http://www.mfe.govt.nz/publications/wast e/end-of-life-tyre-management-ju104/end-oflife-tyre-management.pdf

[2] Eldin N.N. and Senouci A.B. 1993, "Rubbertire particles as concrete aggregate", J. Material in Civil Engineering, ASCE, 5(4), pp.478-496.

[3] Topcu I.B. 1995, "The properties of rubberized concretes", Cement \& Concrete Research, 25(2), pp.304-310.

[4] Khatib Z.K. and Bayomy F.M. 1999, "Rubberized Portland cement concrete", J. Material in Civil Engineering, ASCE, 11(3), pp.206-213.
[5] Fattuhi N.I. and Clark L.A. 1996, "Cement based materials containing shredded scrap truck tire rubber", Construction \& Building Materials, 10(4), pp.229-236.

[6] Hernandez-Olivares F., Barluenga G., Bollati $\mathrm{M}$, and Witoszek B. 2002, "Static and dynamic behavior of recycled tyre rubber-filled concrete", Cement \& Concrete Research, 32(10), pp. 1587-1596.

[7] Segre N. and Joekes I. 2000, "Use of tire rubber particles as addition to cement paste", Cement \& Concrete Research, 30(9), pp.1421-1425.

[8] Bignozzi M.C. and Sandrolini F. 2006, "Tire rubber waste recycling in self-compacting concrete", Cement \& Concrete Research, 36(4), pp.735-739.

[9] Topeu I.B. and Avcular N. 1997, "Collision behaviors of nubberized concrete", Cement \& Concrete Research, 27(12), pp.1893-1898.

[10] Badr, A. and Ashour, A.F. 2005, "Modified ACI drop-weight impact test for concrete", ACI Materials J., 102(4), pp. 249-255.

[11] ACl 544.2R-89 (Reapproved 1999), MCP2005 2005, "Measurement of Properties of Fiber Reinforced Concrete", Reported by ACI Committee 544, on CD, American Concrete Institute.

[12] Sallam H.E.M., Azmy A.M., Sherbini A.S, and El-Barbary M.I. 2007, " Effect of volume fraction of fine aggregate on the mechanical properties and impact resistance of HSC and FRC", $9^{\text {th }}$ Int. Conf. of Al-Azhar Eng., on CD, Paper Code:C9, April 12 - 14, Cairo, Egypt.

[13] Balaha, M. M., Badawy, A. A. M and Hashish, M., (2007), "Effect of using ground waste tire rubber as fine aggregate on the behavior of concrete mixes", Indian Journal of Engineering \& Materials Sciences Vol. 14, December 2007, pp. $427-435$ 